\title{
MODELAGEM ESPACIAL DA ILHA DE CALOR URBANA EM PRESIDENTE PRUDENTE (SP) - BRASIL
}

\author{
AMORIM, Margarete Cristiane de Costa Trindade - mccta@fct.unesp.br \\ Professora Doutora - Faculdade de Ciências e Tecnologia - Universidade Estadual \\ Paulista - UNESP Presidente Prudente - São Paulo - Brasil \\ DUBREUIL, Vincent - vincent.dubreuil@uhb.fr \\ Professor Doutor - Universidade de Rennes 2, LETG-Rennes-COSTEL/França \\ CARDOSO, Renata dos Santos - renatacardoso16@gmail.com \\ Mestranda da Faculdade de Ciências e Tecnologia - Universidade Estadual \\ Paulista - UNESP Presidente Prudente - São Paulo - Brasil
}

\begin{abstract}
RESUMO: O diagnóstico das ilhas de calor urbanas tem se mostrado um instrumento importante para a gestão do espaço urbano, na medida em que a espacialização das diferenças das temperaturas intraurbanas e rurais próximas pode oferecer subsídios para que atitudes possam ser tomadas com o objetivo de amenizar a magnitude de tais ilhas de calor. Entretanto, as interpolações dos registros de temperaturas do ar que não levam em consideração as características dos alvos superficiais produzem resultados que dificultam intervenções mais localizadas. O objetivo deste artigo foi apresentar um conjunto de procedimentos para a modelagem das ilhas de calor urbanas, com o propósito de estimar a temperatura do ar considerando-se as características da superfície (uso da terra, vegetação, relevo). Para isso foram processadas relações entre as temperaturas do ar medidas por meio de transectos móveis; o uso da terra tendo como base as imagens do satélite Landsat 8; o NDVI (Índice de Vegetação por Diferença Normalizada); e a hipsometria.Com essas informações foram feitas relações estatísticas entre a intensidade da ilha de calor urbana nos locais onde as temperaturas foram registradas e os parâmetros geográficos, tais como porcentagem de vegetação, densidade de edificações e altitude.Os resultados mostraram que o modelo gerado estimou satisfatoriamente $(r=0,81)$ a temperatura do ar no ambiente intraurbano e rural próximo, sendo possível subsidiar intervenções mais localizadas que podem contribuir para amenizar a ilha de calor atmosférica que, no episódio estudado (30/06/2014), apresentou-se com forte magnitude e intensidade de $9^{\circ} \mathrm{C}$.
\end{abstract}

PALAVRAS-ChAVE: Ilha de calor; Landsat 8; Modelagem; Presidente Prudente (SP) Brasil.

MODELING SPACE OF URBAN HEAT ISLAND IN PRESIDENTE PRUDENTE (SP) - BRAZIL

ABSTRACT: The diagnosis of urban heat islands have demonstrated to be an important instrument to manage the urban space since the identification of intra-urban temperatures differences and of those in nearby rural areas may offer subsidies for measures intended to alleviate the magnitude of such heat islands. However, interpolations of air temperature records do not consider surface targets characteristics, and produce results that render difficult more localized interventions. The objective of this article is to present a set of procedures for the modeling of urban heat island, in order to estimate the air temperature, taking into consideration surface characteristics (land use, vegetation, and relief). For that, relations between airs temperatures measured by means of mobile transects, land use based on Landsat 8 satellite images, NDVI (Normalized Difference Vegetation Index) and hypsometry were processed. With that information, statistical relations were performed between the urban heat island intensity in locations where temperatures were recorded and the geographic parameters, such as 
vegetation percent, density of buildings and altitude. Results showed how the model generated estimated satisfactorily $(r=0.81)$ the air temperature in intra-urban and nearby rural spaces, making it possible to provide more localized interventions that can contribute to alleviate the atmospheric heat island, which, in the episode studied $(06 / 30 / 2014)$ has presented a strong magnitude and $9^{\circ} \mathrm{C}$ intensity.

KEYWORDS: Heat island; Landsat 8; Modeling; Presidente Prudente (SP) - Brazil.

\section{INTRODUÇÃO}

As ilhas de calor urbanas têm sido verificadas na maioria das cidades onde os estudos foram realizados com intensidades e magnitudes que dependem da combinação das características geoambientais e urbanas dos diferentes sítios, associadas aos sistemas atmosféricos atuantes (MONTEIRO, 1976; OKE, 1987; ARNFIELD, 2003).

Particularmente no ambiente tropical, que naturalmente apresenta situações de estresse térmico, a população sofre com os efeitos das temperaturas elevadas percebidas pelo desconforto térmico agravado pelas ilhas de calor urbanas (AMORIM, 2005; 2010; MENDONÇA; DUBREUIL, 2002). Além disso, não bastasse tal desconforto, outro agravante se refere à concentração de poluentes, pois dependendo da magnitude das ilhas de calor, a poluição do entorno é carreada para as áreas de maior temperatura onde a pressão atmosférica é menor.

Sob a atuação de sistemas polares que resultam em baixas temperaturas, inclusive no ambiente tropical, as ilhas de calor poderiam ser benéficas para as pessoas, entretanto, a presença de poluentes nas áreas mais quentes pode trazer agravamentos para a saúde, particularmente para os grupos humanos mais vulneráveis como os idosos e as crianças.

Deste modo, pesquisas dessa natureza são importantes porque a maior parte da população em escala planetária vive nas cidades e, no Brasil, segundo o censo realizado pelo Instituto Brasileiro de Geografia e Estatística em 2010, $84,4 \%$ (169,9 milhões) das pessoas vivem em áreas urbanas.

O diagnóstico das ilhas de calor urbanas tem se mostrado um instrumento importante para a gestão do espaço urbano (DUBREUIL et al., 2010 a e b), na medida em que a espacialização das diferenças das temperaturas intraurbanas e rurais próximas pode oferecer subsídios para amenizar a magnitude de tais ilhas de calor.

Entretanto, muitas vezes os resultados das pesquisas realizadas não são devidamente utilizados pelo poder público devido à falta de detalhamento da distribuição da temperatura do ar nos ambientes intraurbanos. Ou seja, não são devidamente representadas em um mapa as características do uso da terra e do relevo e suas respectivas temperaturas.

Diante desses fatos, o objetivo deste artigo foi apresentar um conjunto de procedimentos para a modelagem das ilhas de calor urbanas, com o propósito de estimar a temperatura do ar no ambiente urbano e rural próximo, considerandose os detalhes das características da superfície (uso da terra, vegetação, relevo) sendo possível, então, contribuir para intervenções mais localizadas que podem amenizar as ilhas de calor atmosféricas. 
Essa técnica de representação das ilhas de calor oferece um avanço significativo em relação às formas tradicionais de representações cartográficas por meio de interpolações. Tais interpolações das temperaturas do ar, embora muito úteis do ponto de vista da visualização da distribuição da temperatura, não levam em consideração as características dos alvos superficiais e do relevo e produzem resultados que dificultam intervenções mais localizadas.

A presente pesquisa foi realizada em Presidente Prudente, cidade localizada no oeste do Estado de São Paulo (Figura 1), com população aproximada de 207.625 habitantes (Censo do IBGE, 2010). Tal cidade possui um período quente e chuvoso entre outubro e março, e outro mais ameno e seco, entre abril e setembro. Em pesquisas anteriores foram diagnosticadas ilhas de calor atmosféricas de alta magnitude em diferentes episódios, identificadas por meio de registros de temperaturas em transectos móveis (AMORIM, 2005) e em pontos fixos (AMORIM, 2000). Não são raros os eventos de temperaturas elevadas que provocam muito desconforto para a população e, dependendo das características intraurbanas, esses eventos são intensificados pela geração das ilhas de calor (AMORIM, 2000; 2005).

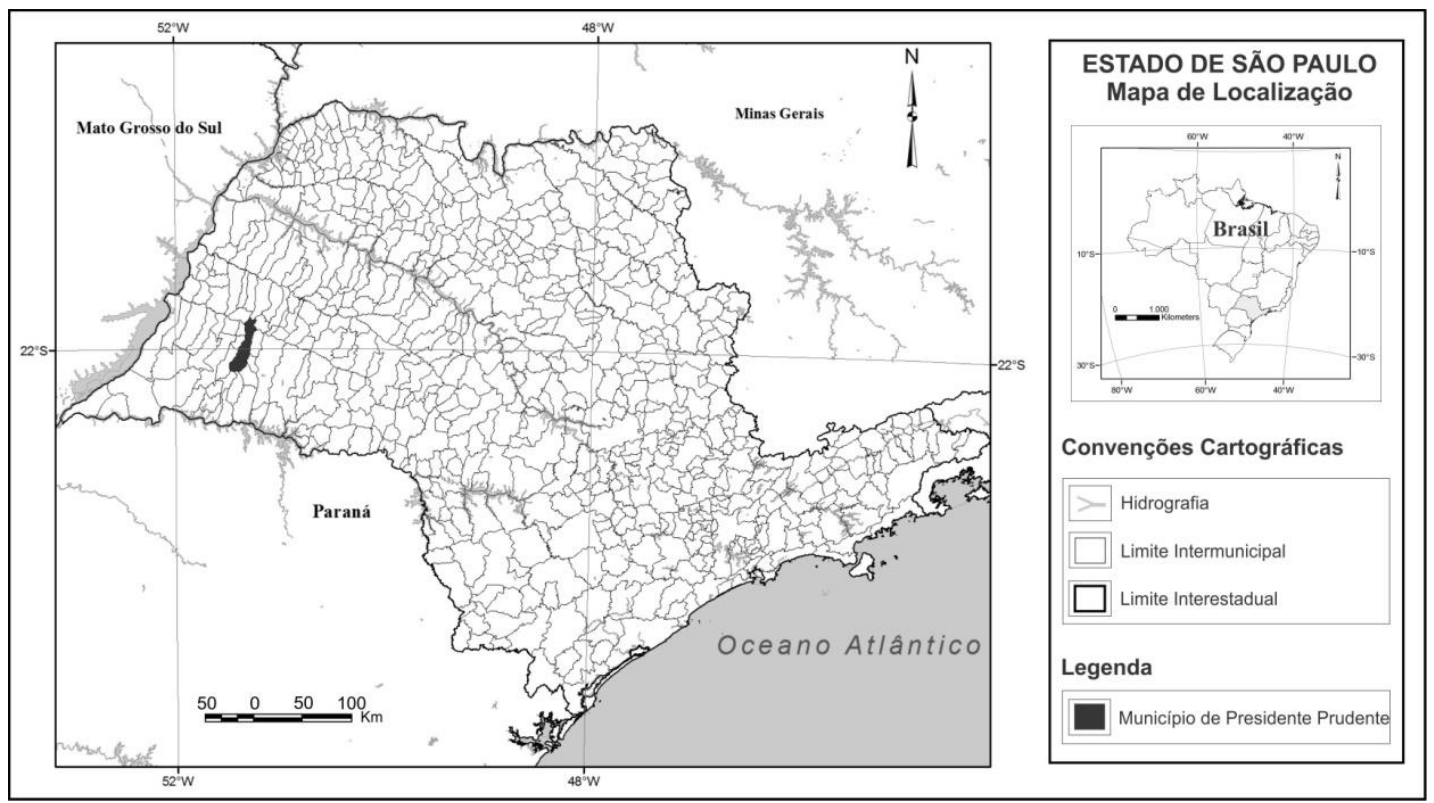

Figura 1: Localização de Presidente Prudente no Estado de São Paulo. Fonte: Malhas digitais do IBGE. Org. Cardoso, R. S.

\section{A ilha de calor urbana e sua representação espacial}

O clima urbano é submetido a uma forte variabilidade espacial devido às rápidas mudanças no uso da terra que mudam localmente e rapidamente as características da ilha de calor urbana.

No processo de compreensão do efeito do urbano na atmosfera próxima à superfície, Oke (2006) destaca que se deve avaliar: a estrutura urbana (a dimensão das edificações e os espaços entre elas, a largura das vias e o espaçamento entre elas); a cobertura da superfície (construída, pavimentada, 
com cobertura vegetal, solo descoberto, água); o tecido urbano (resultante do processo de expansão do fenômeno urbano, suas continuidades e descontinuidades); e o metabolismo urbano (água, calor e poluentes devido à atividade humana).

Stewart e Oke (2009) criaram uma classificação centrada na paisagem e, partindo da avaliação global do conjunto da paisagem, os autores a decompuseram, em um primeiro momento, seguindo o princípio da modificação da superfície, ou seja, o grau em que o aspecto técnico-cultural se sobrepõe à superfície físico-natural.

Oke (2006) destaca que a importância das zonas climáticas urbanas não está em sua absoluta precisão para descrever o local, mas a sua capacidade de classificar as áreas de um bairro em setores, que são semelhantes em sua capacidade de modificar o clima local.

Para diagnosticar as ilhas de calor urbanas e se produzir a representação espacial das mesmas, a maioria dos estudos utiliza transectos móveis (AMORIM et al., 2009) ou, às vezes, quando os recursos permitem, instalação de uma densa rede de estações automáticas (QUENOL et al., 2010). No entanto, o conhecimento real do clima local permanece em grande parte obscuro em detalhe, particularmente, no que se refere à sua representação espacial, de maneira que consiga se aproximar das características da superfície e de uma classificação da paisagem conforme proposta de Stewart e Oke (2009).

A espacialização da temperatura do ar baseada nos valores medidos associados às características da superfície, conforme se propõe neste artigo, oferece um avanço significativo em relação às formas tradicionais de representações cartográficas por meio de interpolações. Tais interpolações não levam em consideração as características do uso da terra e as características do relevo, como, por exemplo, pode-se verificar na Figura 2. 


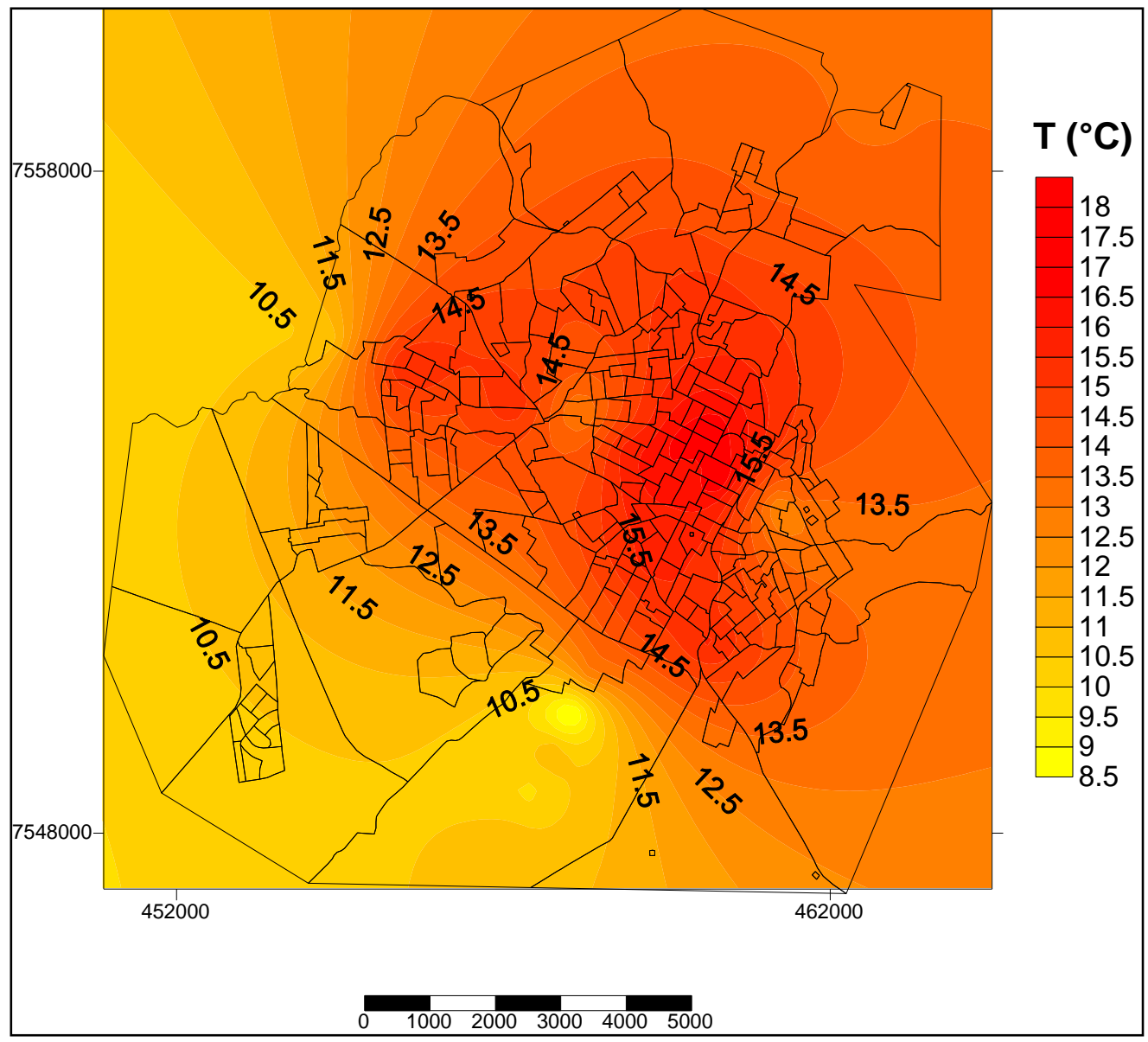

Figura 2: Presidente Prudente: temperatura do ar - 30/06/2014 - 21h Elaboração: AMORIM, M.C.C.T.

Vários autores têm proposto metodologias que utilizam um SIG (Sistema de Informação Geográfica) para interpolar as temperaturas do ar através da incorporação de bases de dados finas com escala, tais como a altura dos edifícios, superfícies impermeáveis, vegetação, etc (OKE, 2007; FOISSARD et al., 2013). Esses métodos pressupõem o acesso a uma riqueza de informações, muitas vezes disponíveis em países desenvolvidos, mas não necessariamente para os outros.

As imagens do satélite Landsat, sobretudo a banda térmica, têm sido utilizadas para fazer a interpolação da temperatura do ar em função da temperatura da superfície (MENDONÇA; DUBREUIL, 2005; AMORIM et al., 2009). Entretanto, além da diferença entre os tipos de temperaturas (da superfície e do ar), a banda térmica levanta a questão do momento da aquisição da imagem Landsat: as imagens são tomadas no início do dia, enquanto a ilha de calor urbana atinge sua intensidade máxima no início da noite.

Assim, este artigo propõe uma nova metodologia para a modelagem da ilha de calor urbana a partir de uma campanha de campo e de imagens do satélite Landsat 8. 


\section{PROCEDIMENTOS METOdOLÓgICOS}

Para o registro das temperaturas do ar intraurbana, no período noturno em Presidente Prudente, foram realizados transectos móveis nos percursos sulnorte e oeste-leste, totalizando 40 pontos da área urbana e rural próxima, levando-se em consideração as características da superfície, como, por exemplo, o uso da terra, o relevo, a densidade de construções e de vegetação arbórea (Figura 3).

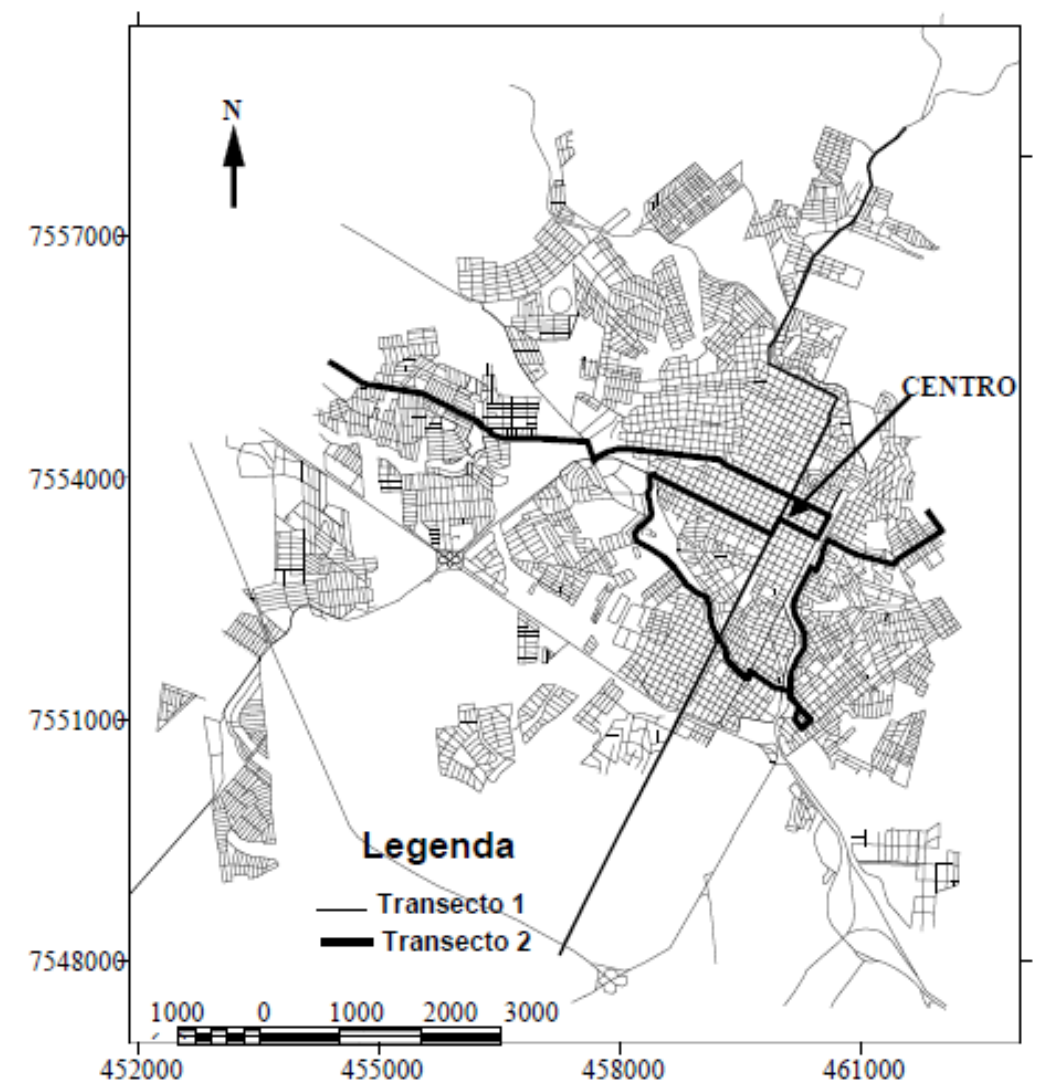

Figura 3: Percursos realizados para os registros das temperaturas.

Elaboração: AMORIM, M.C.C.T.

Foram utilizados sensores digitais, acoplados a uma haste de madeira com $1,5 \mathrm{~m}$ de comprimento na lateral de dois veículos que saíram da periferia (rural), passando pelo centro, chegando ao extremo oposto da cidade. As medições se iniciaram às $21 \mathrm{~h}$ e não ultrapassaram 50 minutos. Este horário é adequado para este tipo de registro, uma vez que as temperaturas não experimentam naturalmente mudanças rápidas.

O processo de realização da modelagem das ilhas de calor urbana foi realizado no aplicativo IDRISI ${ }^{1}$ e se iniciou com a elaboração do mapa de uso da terra a partir de uma classificação da imagem Landsat 8 (bandas 3, 5 e 4),

\footnotetext{
${ }^{1}$ Idrisi é marca registrada da Clark University. 
adquiridas gratuitamente no site http://earthexplorer.usgs.gov/, cujas aplicações são apresentadas na tabela 1.

Tabela 1: Intervalo espectral e aplicações das bandas 3,5 e 4 do satélite Landsat 8

\begin{tabular}{ccc}
\hline Banda & $\begin{array}{c}\text { Intervalo } \\
\text { espectral }\end{array}$ & Aplicações \\
\hline 3- Green & $\begin{array}{c}0.53-0.59 \\
\mu \mathrm{m}\end{array}$ & $\begin{array}{c}\text { Evidencia a vegetação para a avaliação do vigor das } \\
\text { plantas }\end{array}$ \\
$\begin{array}{c}5 \text { - Near } \\
\text { Infrared }\end{array}$ & $\begin{array}{c}0.85-0.88 \\
\mu \mathrm{m}\end{array}$ & $\begin{array}{c}\text { Evidencia o teor de biomassa } \\
4-\text { Red }\end{array}$ \\
$\begin{array}{c}0.64-0.67 \\
\mu \mathrm{m}\end{array}$ & $\begin{array}{c}\text { Discrimina a vegetação em função do conteúdo em } \\
\text { clorofila }\end{array}$ \\
\hline
\end{tabular}

Fonte: http://landsat.usgs.gov/best spectral bands to use.php

As três bandas possibilitaram a elaboração de uma composição colorida que diferencia as áreas urbanas e rurais (Figura 4) e foi utilizada, juntamente com trabalhos de campo e conhecimento do terreno, para auxiliar na classificação do uso da terra. Na sequência, por meio da junção das bandas 4 e 5 gerou-se o NDVI (Índice de Vegetação por Diferença Normalizada), que permite identificar a densidade de vegetação e sua distribuição (Figura 5). A escala gerada nesta carta permite diferenciar as áreas urbanas (construções e arruamentos), nos valores menores, das que possuem vegetação com densidades variadas (alta, média e baixa). Os valores maiores se referem às maiores densidades de vegetação e vice-versa.

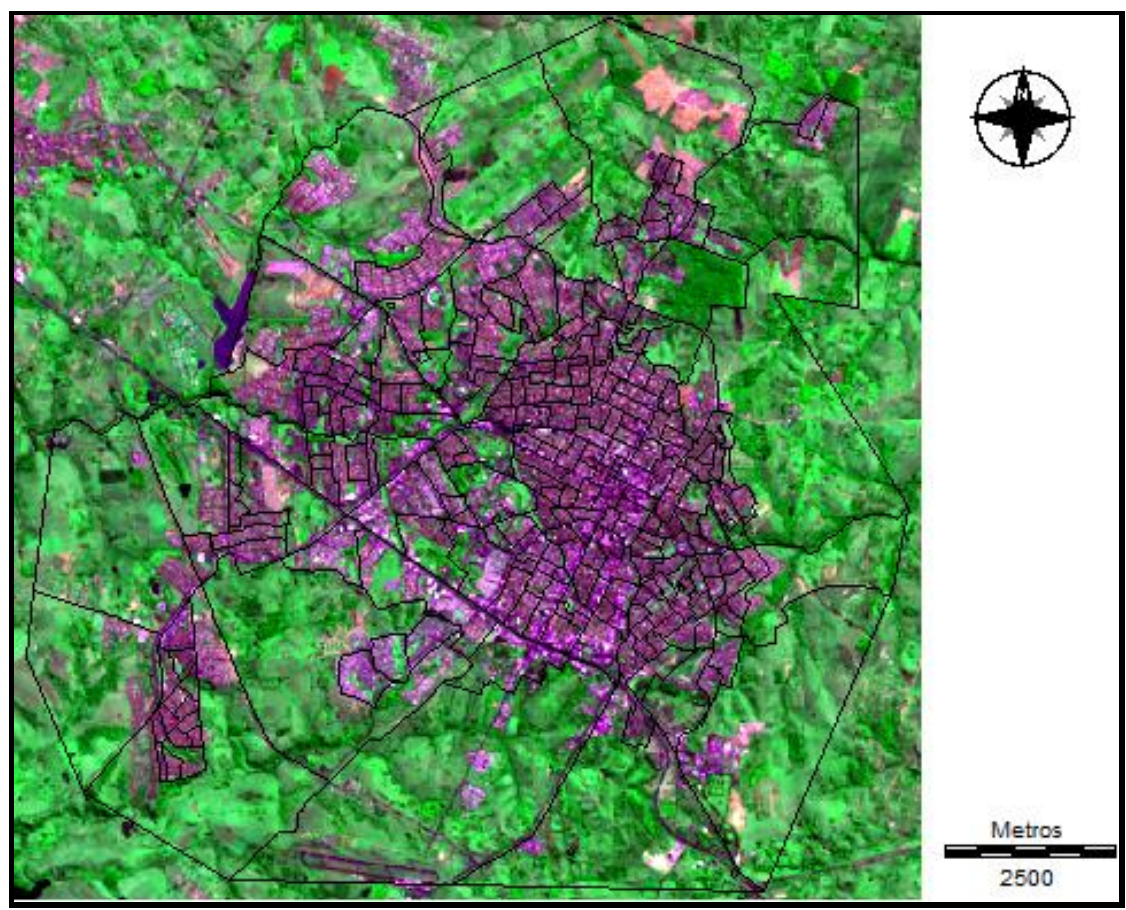

Ano 11 - Vol. 16 - JAN/JUL 2015 
Figura 4: Composição colorida de Presidente Prudente (SP), elaborada a partir das bandas 3, 5 e 4 da imagem Landsat 8, 08/08/2014. Fonte da imagem: http://earthexplorer.usgs.gov/ Elaboração: AMORIM, M.C.C.T.

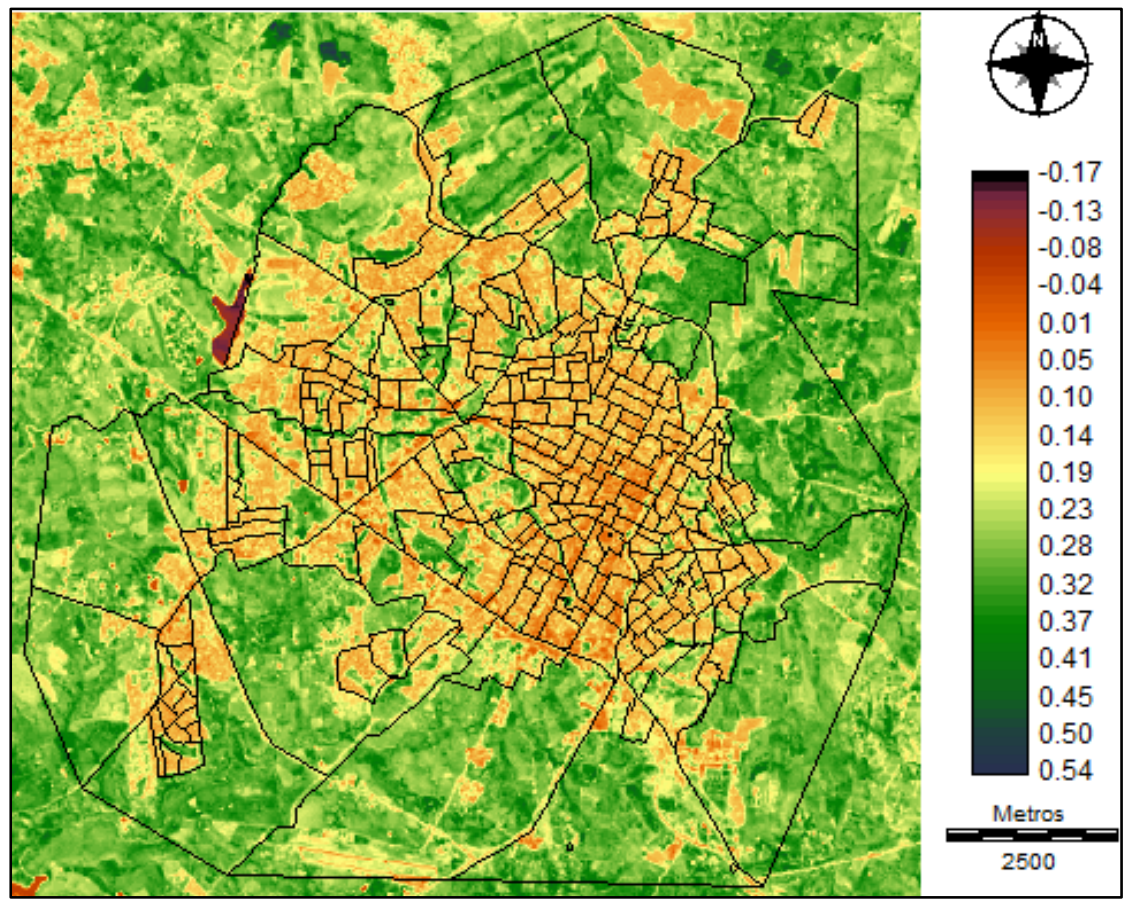

Figura 5: Carta de NDVI de Presidente Prudente (SP), elaborada a partir das bandas 4 e 5 da imagem Landsat 8, 08/08/2014.Fonte da imagem: http://earthexplorer.usgs.gov/ Elaboração: AMORIM, M.C.C.T.

Utilizando-se das bandas 3,5 , e 4 do Landsat 8 e da carta de NDVI (Figura 5) se processou a classificação automática do uso da terra, no Idrisi, por Cluster (Figura 6). 


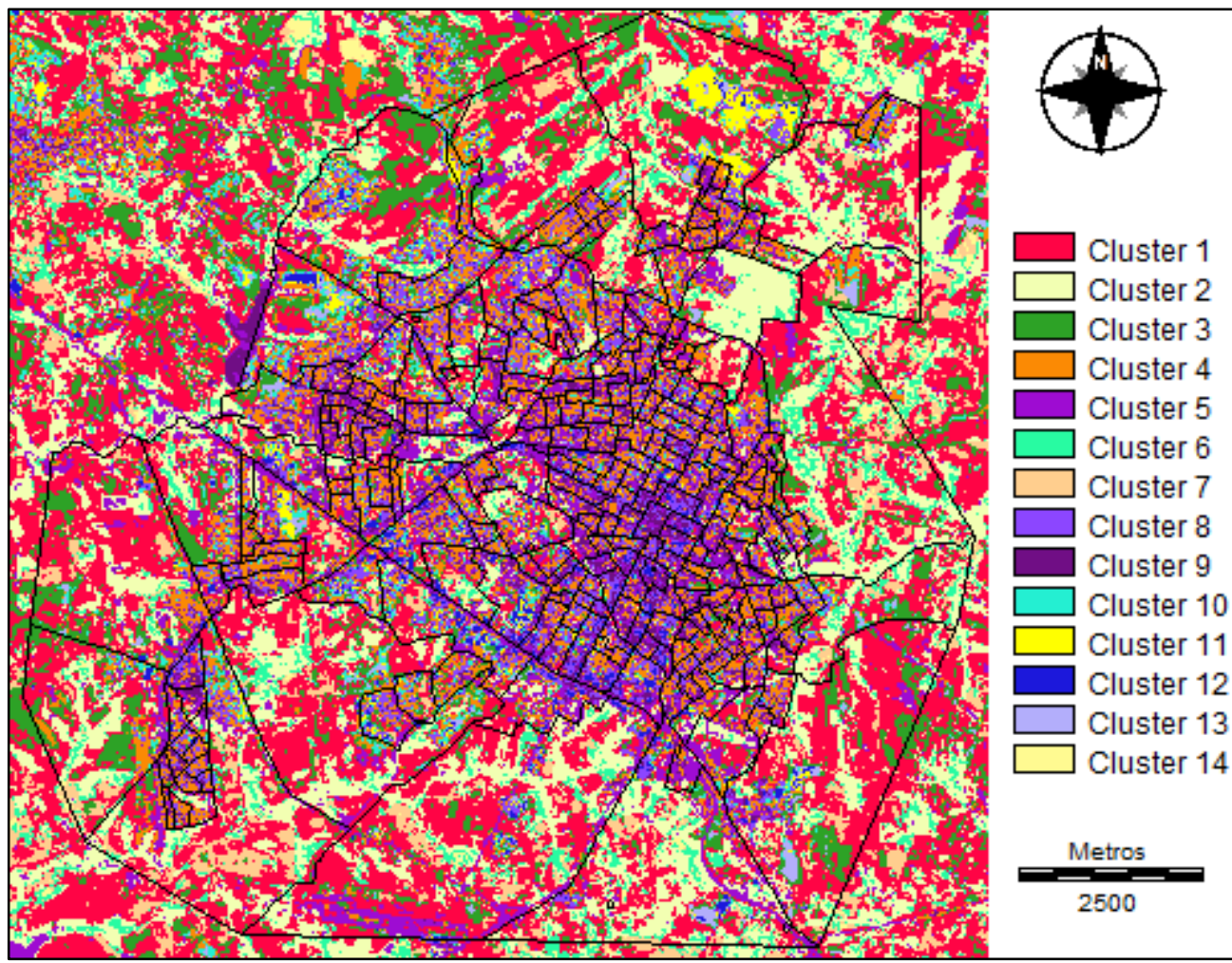

Figura 6: Classificação por Cluster de Presidente Prudente (SP), elaborada a partir das bandas 3, 5 e 4 da imagem Landsat 8 e do NDVI, 08/08/2014.Fonte da imagem: http://earthexplorer.usgs.gov/Elaboração: AMORIM, M.C.C.T.

A partir da classificação inicial (Figura 6) se realizou o agrupamento das classes por meio da análise da carta de composição colorida (Figura 4) e do conhecimento de campo. A classificação final foi reduzida em três classes levando-se em consideração o elemento que predominou em cada pixel: construções, vegetação rasteira e vegetação densa (Figura 7). Essas classes foram escolhidas por serem fundamentais para diferenciar as temperaturas do ar e contribuir para a geração das ilhas de calor urbana. A classe "vegetação densa" reuniu as áreas com cobertura vegetal arbórea presentes nas áreas verdes urbana, nos parques e nos fundos de vale. A "vegetação rasteira" considerou as pastagens, os terrenos urbanos sem construções e com presença de gramados. A classe "construções" agrupou todas as áreas impermeabilizadas tanto com alta, média e baixa densidade de construções como as vias pavimentadas.

$\mathrm{Na}$ sequência foi calculado o centro geométrico para se considerar no resultado final a distância do centro da cidade. 


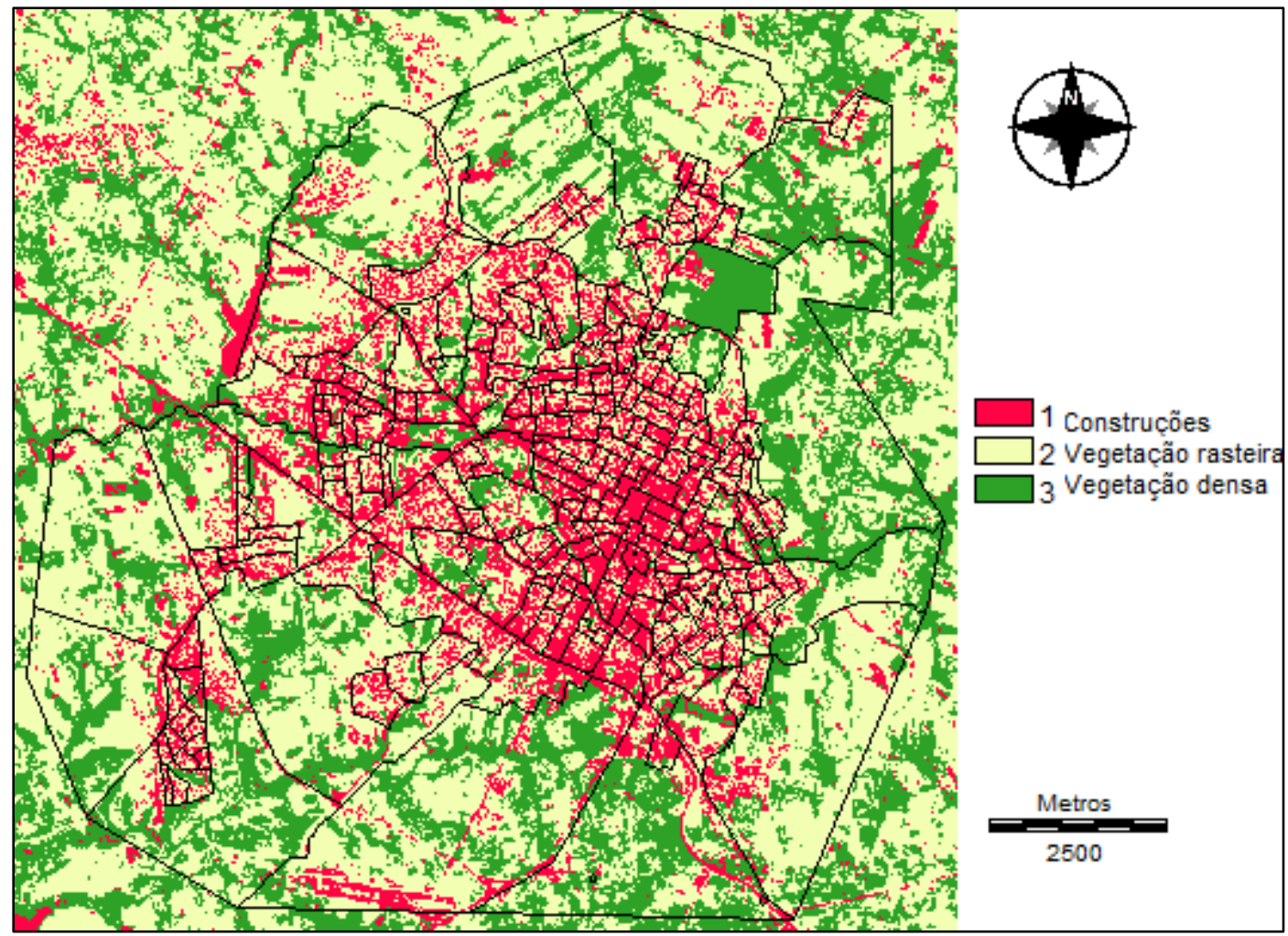

Figura 7: Carta de uso da terra agrupada a partir da Figura 4.Fonte da imagem: http://earthexplorer.usgs.gov/Elaboração: AMORIM, M.C.C.T.

Com o objetivo de calcular a relação entre a temperatura do ar e o uso da terra, inicialmente buscou-se calcular quantos pixels de cada classe estavam no entorno de cada ponto de temperatura medida no transecto. Assim, chegou-se à correlação entre a temperatura do ar medida e a frequência de cada classe de uso da terra em janelas móveis de tamanho variável entre $3 \times 3$ pixels $(90 \times 90$ metros), $5 \times 5$ pixels $(150 \times 150$ metros) e de $9 \times 9$ pixels $(270 \times 270$ metros $)$ e assim por diante, considerando que a resolução espacial do Landsat 8 nas bandas selecionadas é de 30 metros. Esse procedimento é fundamental porque não se sabe inicialmente qual a área de influência do uso da terra sobre as medidas de temperatura para cada ponto e isso justifica o teste com essas janelas de tamanho "móveis".

No presente estudo, as melhores correlações estatísticas entre as classes 1 (construções), 2 (vegetação rasteira) e 3 (vegetação densa) e a temperatura do ar foram $33 \times 33$ pixels (990 x 990 metros). No caso da classe 1, por exemplo, a correlação entre a temperatura do ar e a porcentagem desse tipo do uso da terra passou de 0,55 na janela de $5 \times 5$ pixels para 0,74 na janela de $33 \times 33$. Na classe 2, passou de 0,37 na janela $5 \times 5$, para 0,54 na $33 \times 33$ e na classe 3 , passou de 0,47 na $5 \times 5$ para 0,60 na $33 \times 33$.

O relevo é um importante fator do clima que interfere na distribuição da temperatura do ar. Para incorporá-lo na modelagem, buscou-se a hipsometria da área urbana de Presidente Prudente e rural próxima no site http://www.webmapit.com.br/inpe/topodata (Figura 8). 


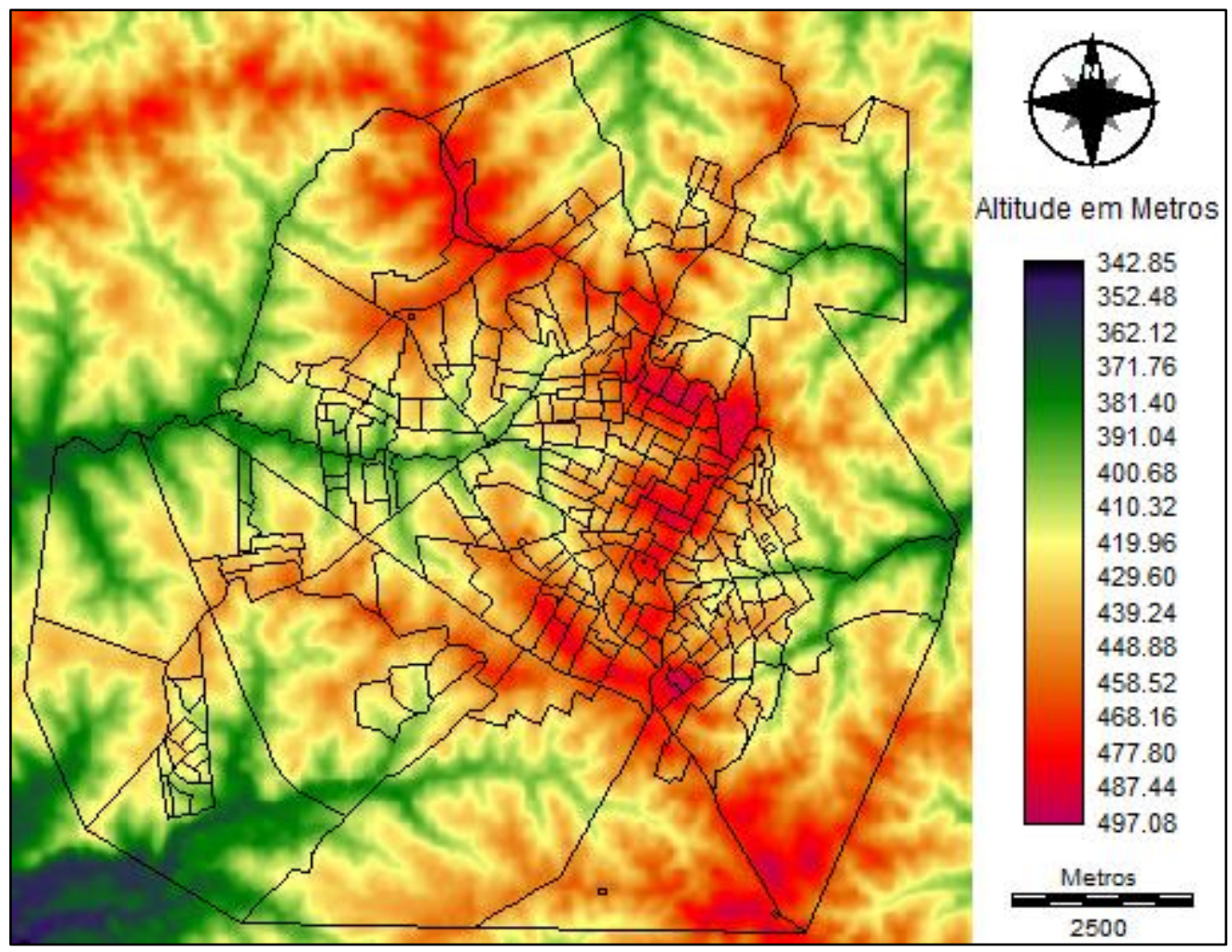

Figura 8: Carta Hipsométrica de Presidente Prudente.

Fonte da imagem: http://www.webmapit.com.br/inpe/topodata Elaboração: DUBREUIL, V.

Com essas informações foram feitas relações estatísticas e uma regressão múltipla entre a intensidade da ilha de calor atmosférica nos locais onde as temperaturas foram registradas e os parâmetros geográficos da superfície, tais como porcentagem de vegetação, densidade de edificações e altitude. O modelo discriminou os melhores indicadores espaciais para cada categoria de forma a estimar os resultados para toda a imagem através de regressão linear múltipla.

\section{RESULTADOS E DISCUSSÕES}

No dia da realização do transecto móvel noturno, ocorrido em 30 de junho de 2014, às $21 \mathrm{~h}$, registrou-se ilha de calor de muito forte magnitude que atingiu a intensidade de $9^{\circ} \mathrm{C}$, segundo a classificação de García (1996). A atmosfera estava estável, sem vento e sem precipitação, sob a atuação de uma massa Polar Atlântica. Na estação meteorológica da FCT/UNESP de Presidente Prudente, registrou-se temperatura de $13,8^{\circ} \mathrm{C}$ às $21 \mathrm{~h}$ (horário local). $\mathrm{O}$ vento fraco predominante durante o dia foi de sudeste.

Nos dois percursos as menores temperaturas foram registradas nos ambientes rurais ou próximos a eles (entre 8 e $11^{\circ} \mathrm{C}$ ) e nas áreas com ocupação dispersa. As maiores temperaturas foram registradas nos bairros populares 
adensados, nos comerciais e nos verticalizados (entre 15 e $18^{\circ} \mathrm{C}$ ), como se constata no Gráfico 1.

Gráfico 1: Temperaturas medidas nos dois percursos realizados em Presidente Prudente nos sentidos Sul-Norte e Oeste-Leste, no dia 30 de junho de 2014.

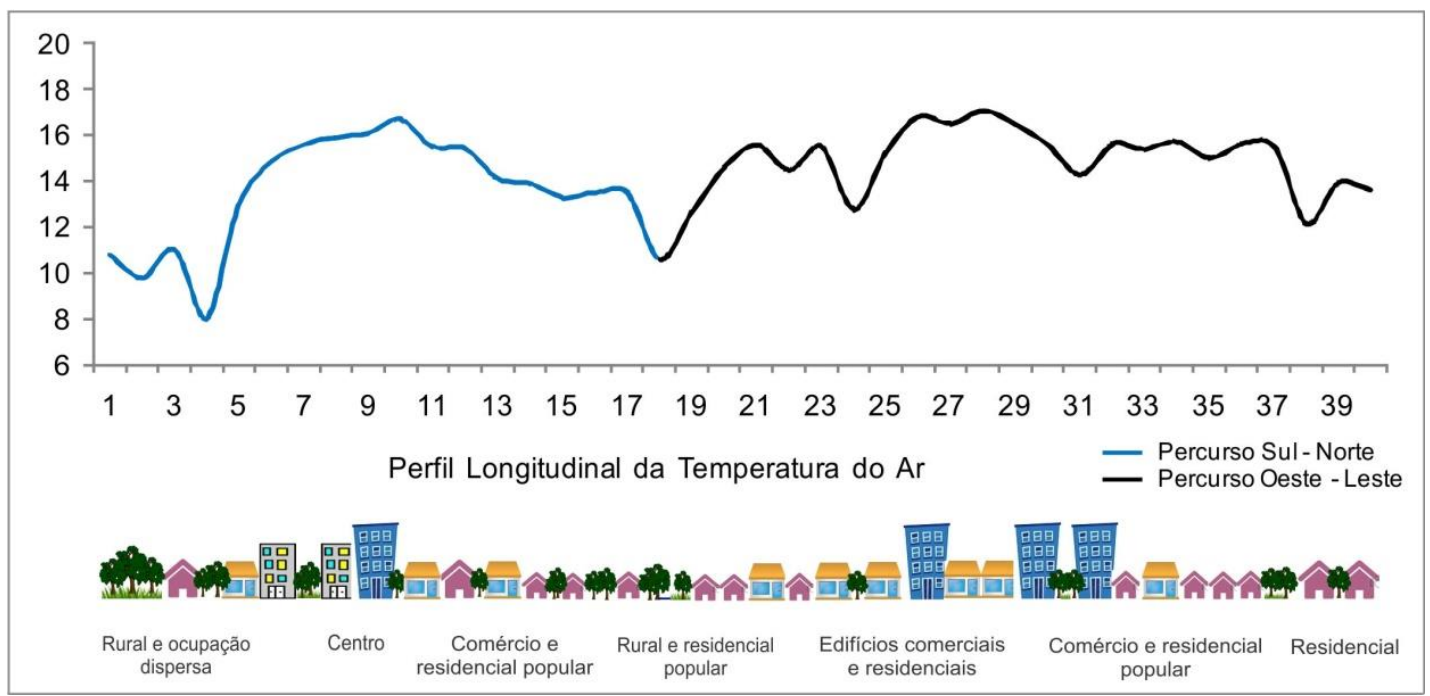

Elaboração: Cardoso, R. S. (inspirado em Dubreuil et al., 2010b)

Com o objetivo de analisar a ilha de calor atmosférica diagnosticada em Presidente Prudente no referido episódio, elaborou-se a modelagem das temperaturas do ar generalizadas em cada ponto, conforme descrito nos procedimentos metodológicos deste artigo.

A melhor correlação foi obtida com a seguinte fórmula:

$\mathrm{Ta}=1.65+0.17^{*} \mathrm{C} 1-0.08^{*} \mathrm{C} 3-0.14 * \mathrm{D}+0.03^{*} \mathrm{~A}$

com:

$\mathrm{Ta}=$ temperatura do ar modelizada

C1: porcentagem da classe 1 (construções) no uso da terra dentro da janela $33 \times 33$ pixels em torno da cada estação

C3: porcentagem da classa 3 (vegetação densa) no uso da terra dentro da janela $33 \times 33$ pixels em torno da cada estação

D : distância no centro da cidade

A : altitude

A correlação global foi de 0.81 , conforme se verifica nas informações contidas no quadro 1. Cabe destacar que a correlação com esses três parâmetros foi melhor que a correlação com cada parâmetro separadamente. Também é importante lembrar que com esse método, os parâmetros devem ficar estatisticamente independentes, ou seja, com correlações baixas entre eles. 


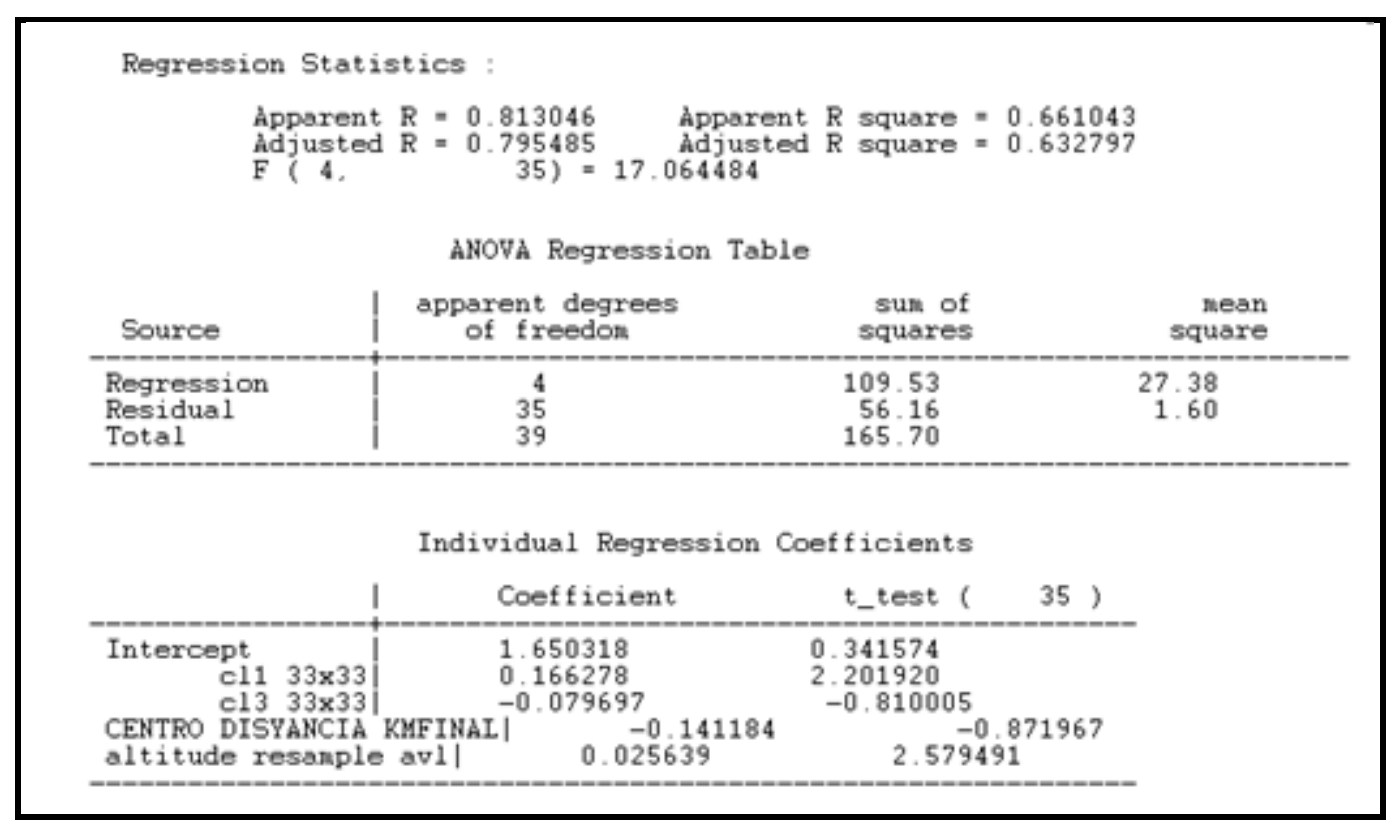

Quadro 1: Resultados da regressão estatística da fórmula utilizada na modelagem

Nota-se que, no final, apenas as classes de uso da terra "construções" e "vegetação densa" foram utilizadas na modelagem. Os coeficientes mostraram que o papel mais forte (positivo) foi da classe "construções", com o coeficiente de correlação (0.74) e multiplicador (0.17 na fórmula da Ta - temperatura do ar modelizada) maiores. Na estimação final, isso significa a importância maior das construções para gerar a ilha de calor urbana e assim modelar a temperatura nessa escala. A classe "vegetação densa" teve um coeficiente negativo $(-0.08)$, ou seja, evidenciou o papel da vegetação densa para reduzir a temperatura. 0 coeficiente foi menor na equação da Ta, mostrando o papel "secundário" da vegetação densa na estimação da Ta (temperatura do ar modelizada). O modelo mostrou também o efeito global da ilha de calor urbana com temperaturas decrescentes do centro para a periferia. Vale a pena destacar que o efeito da vizinhança do uso da terra sobre a temperatura funcionou menos com os pixels próximos e mais dentro de janelas maiores (33×33) mostrando o efeito global do uso da terra (Foissard et al., 2013). Esta metodologia está assim bem adequada na escala de estudo das cidades médias, minimizando os efeitos microclimáticos e permitindo uma cartografia na escala da aglomeração.

A Figura 9 mostra os resultados da modelagem com as temperaturas estimadas para a área de estudo com essa fórmula. A distribuição das temperaturas no intraurbano e no entorno rural se apresentaram entre 8 e $18^{\circ} \mathrm{C}$. $\mathrm{O}$ núcleo da ilha de calor urbana com temperaturas estimadas entre 17 e $18^{\circ} \mathrm{C}$ ocorreu no centro comercial (Figura 9 - A) densamente edificado e pouco arborizado, mas não se restringiu a ele e se prolongou ao norte e ao sul, em áreas densamente construídas nos bairros considerados residenciais. Nestes as temperaturas ficaram entre 15 e $17^{\circ} \mathrm{C}$. Os bairros mais afastados do centro, densamente construídos e com baixa quantidade de cobertura vegetal arbórea apresentaram temperaturas entre 14 e $16^{\circ} \mathrm{C}$. Já os bairros também periféricos, mas com menor densidade de construções e com cobertura vegetal arbórea 
tiveram temperaturas entre 13 e $14^{\circ} \mathrm{C}$. As áreas do entorno rural próximo com predomínio de pastagens tiveram temperaturas que variaram entre 10 e $13^{\circ} \mathrm{C}$. Nos fundos de vales e nas áreas com densa cobertura vegetal arbórea as temperaturas ficaram entre 8 e $10^{\circ} \mathrm{C}$.

Os condomínios fechados de alto padrão construtivo, com terrenos grandes e arborizados e gramados, localizados ao sul da malha urbana (Figura 9 - B) apresentaram temperaturas equivalentes ao ambiente rural com pastagens (entre 10 e $13^{\circ} \mathrm{C}$ ). Já os bairros populares dos setores norte (Figura $9-\mathrm{C}$ ) e oeste da malha urbana (Figura 9 - D) com carência de cobertura vegetal arbórea e terrenos pequenos e densamente construídos tiveram temperaturas entre $14 \mathrm{e}$ $16^{\circ} \mathrm{C}$.

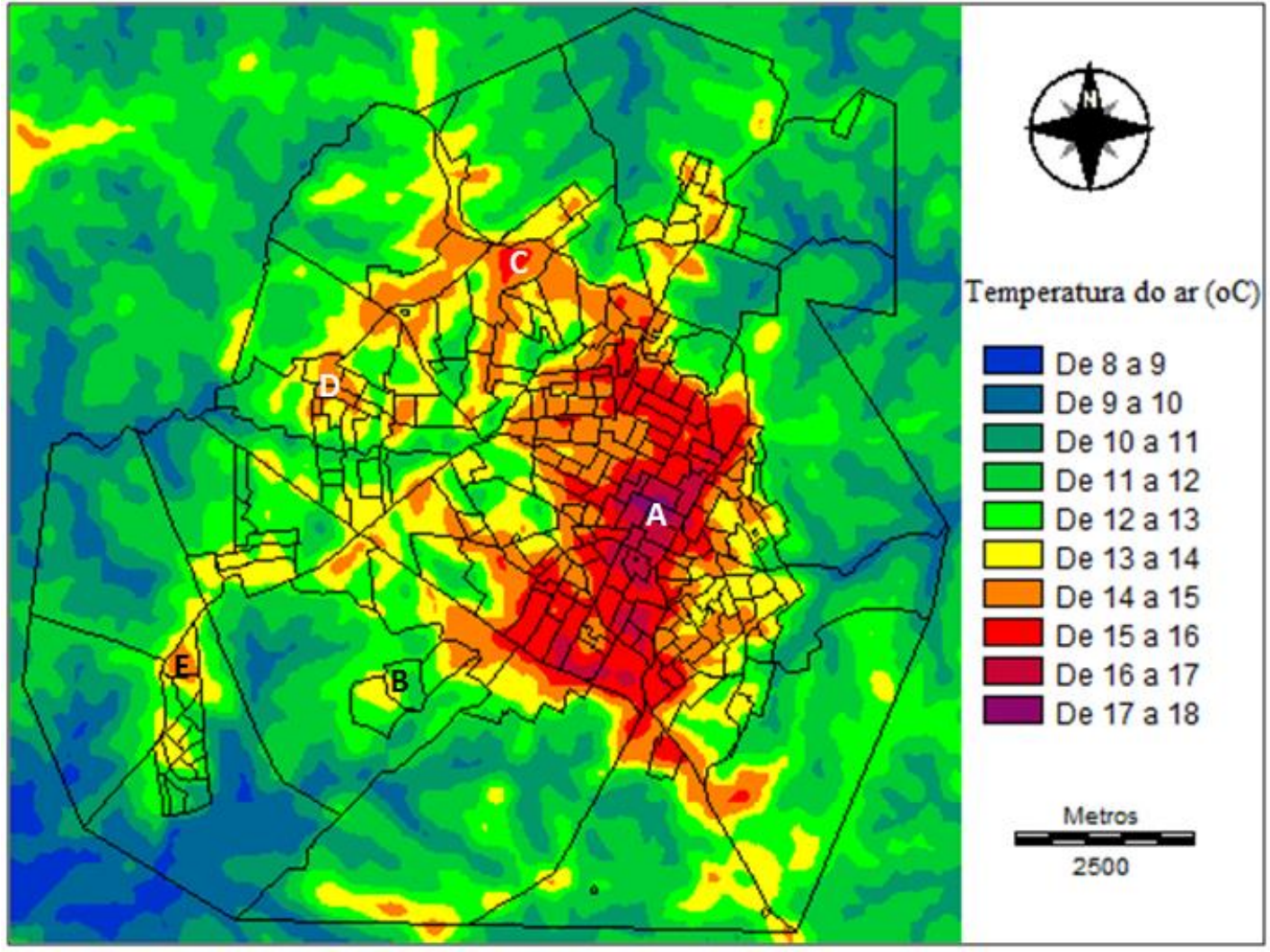

Figura 9: Modelagem das ilhas de calor urbana de Presidente Prudente - 30/06/2014 21h (A - Centro Comercial; B - Condomínios Fechados; C, D, E - Bairros Populares) Elaboração: AMORIM, M.C.C.T; DUBREUIL, V.

O relevo teve um papel primordial na distribuição das temperaturas, particularmente por se tratar da atuação de uma massa polar, pois os fundos de vale, especialmente àqueles com cobertura vegetal arbórea, apresentaram as menores temperaturas. Nesse caso, o relevo mostra uma relação inversa de diminuição da temperatura com a altitude, ou seja, com fenômeno de inversão da temperatura nos fundos de vales. Entretanto, o efeito dos fundos de vale na diminuição das temperaturas foi minimizado naqueles que apresentaram alta densidade de construções e pequena quantidade de cobertura vegetal arbórea. 
Desta forma, o resultado desta pesquisa revelou a formação de ilhas de calor em três aspectos significativos: - a intensidade, como indicativo da magnitude do fenômeno, que se processou com vigor sob a atuação de um sistema atmosférico estável (massa polar); - as variações espaciais, relacionadas à densidade de construções e de cobertura vegetal (arbórea e rasteira) e às características do relevo.

O perfil das ilhas de calor noturnas em Presidente Prudente se aproximou do modelo clássico apresentado por Oke (1974) com as maiores temperaturas registradas no centro e nas áreas densamente construídas. Entretanto, nas áreas periféricas, tal modelo não se repetiu exatamente conforme as características apresentadas pelo autor, ou seja, com as menores temperaturas em decorrência da interferência do rural próximo. As maiores ou menores temperaturas dos bairros periféricos se relacionaram não apenas às especificidades do relevo (fundos de vale com as menores temperaturas), mas principalmente com as características sociais e econômicas da população que resultam em condições de padrões construtivos muito diversos.

Os condomínios fechados localizados na zona sul (Figura 9 - B) da malha urbana, embora na mesma altitude do que os conjuntos habitacionais à sudoeste (Figura $9-\mathrm{E}$ ), apresentaram temperaturas menores (ambos tendo o ambiente rural ao redor). Tais diferenças são explicadas pelo tamanho dos lotes que nos conjuntos habitacionais são muito menores, o que leva a um padrão de adensamento muito maior do que nos condomínios de alto padrão. Além disso, a cobertura vegetal (tanto arbórea como rasteira) também é mais escassa nos conjuntos habitacionais.

Outros "oásis" são claramente perceptíveis no intraurbano de Presidente Prudente e não estão relacionados com a proximidade do ambiente rural, mas sim com a baixa densidade de construções, a quantidade significativa de vegetação arbórea e rasteira e o relevo. No sentido inverso, áreas relativamente próximas ao ambiente rural, possuem temperaturas muito maiores, algumas delas próximas à temperatura da área central, resultantes do adensamento e da carência de vegetação.

\section{CONSIDERAÇÕES FINAIS}

A modelagem da temperatura do ar em Presidente Prudente mostrou que os limites das áreas densamente construídas e com baixa densidade de cobertura vegetal arbórea e rasteira definiram claramente o limite das temperaturas elevadas. As áreas intraurbanas com menor densidade de construções e com presença de cobertura vegetal arbórea estiveram sujeitas às temperaturas mais baixas.

A estimativa da temperatura do ar por meio da modelagem das ilhas de calor urbanas, considerando-se a densidade de construções e de vegetação e o relevo se mostra como um importante instrumento para a gestão do espaço urbano sendo possível contribuir para intervenções mais localizadas que podem amenizar as ilhas de calor atmosféricas.

Assim, conclui-se que a representação espacial da ilha de calor urbana, tradicionalmente utilizada nos estudos de clima urbano, por meio de isotermas, é importante para uma primeira verificação da distribuição espacial da 
temperatura. Entretanto, na perspectiva das possibilidades de intervenções mais pontuais, a modelagem oferece subsídios que podem de fato auxiliar nas políticas que visem, seja do ponto de vista do conforto ou da saúde, contribuir para a mitigação das ilhas de calor urbanas.

\section{AGRADECIMENTO:}

À Fundação de Amparo à Pesquisa do Estado de São Paulo (FAPESP) pelo apoio Financeiro, processo 2014/16350-3.

\section{REFERÊNCIAS BIBLIOGRÁFICAS}

AMORIM, M. C. C. T. O clima urbano de Presidente Prudente/SP. São Paulo, 2000. 374p. Tese (Doutorado em Geografia) - Faculdade de Filosofia, Letras e Ciências Humanas, Universidade de São Paulo.

AMORIM, M. C. C. T. Intensidade e forma da ilha de calor urbana em Presidente Prudente/SP. Geosul (UFSC), v.20, p.65 - 82, 2005.

AMORIM, M. C. C. T. Climatologia e gestão do espaço urbano. Mercator (Fortaleza. Online). , v.9, p.71 - 90, 2010.

AMORIM M.C.C.T., DUBREUIL V., QUENOL H., SANT'ANNA J.L. Características das ilhas de calor em cidades de porte médio: exemplos de Presidente Prudente (Brasil) e Rennes (França). Confins [Online], 7-2009, 16p., http://confins.revues.org/index6070.html

ARNFIELD A.J. Two decades of urban climate research: a review of turbulence, exchanges of energy and water and the urban heat island. International Journal of Climatology; 23, p. 1-26, 2003.

DUBREUIL V., QUENOL H., FOISSARD X., PLANCHON O. Climatologie urbaine et îlot de chaleur urbain à Rennes, in P.Clergeau (dir.) Ville et biodiversité: les enseignements d'une recherche pluridisciplinaire. Presses Universitaires de Rennes, p.105-122, 2010. (a)

DUBREUIL V., DELAHAYE C., LE STRAT A. Dynamiques d'occupation et d'utilisation du sol et leurs impacts climatiques au Mato Grosso, Brésil. Confins [Online], 10-2010, http://confins.revues.org/6845 (b)

FOISSARD X., QUENOL H., DUBREUIL V. Analyse et spatialisation de l'ilot de chaleur urbain dans l'agglomération rennaise. Actes du 26e colloque de I'AIC, Cotonou, Bénin, p.242-247, septembre 2013.

GARCÍA, FERNÁNDEZ F. Manual de climatologia aplicada: clima, medio ambiente y planificación. Madrid: Editorial síntesis, S.A., 1996. 285p.

MENDONÇA F., DUBREUIL V. L'étude du climat urbain au Brésil: Etat actuel et contribution de la télédétection; in Environnement et télédétection au Brésil, Presses Universitaires de Rennes, p.135-146, 2002.

MENDONCA F., DUBREUIL V. Termografia de superfície e temperatura do ar na RMC (Região Metropolitana de Curitiba - PR). Revista RA'E GA - O espaço geográfico em analise, n.9, p.25-35, 2005. 
MONTEIRO, Carlos Augusto de Figueiredo. Teoria e clima urbano. São Paulo: IGEOG/USP, 1976. 181 p. (Série Teses e Monografias, 25).

OKE, T. Review of urban climatology: 1968-1973. Geneva: World Meteorological Organization, 1974 (WMO Technical note, n. 134).

OKE T.R. Boundary Layer Climates. Routledge, 435p., 1987.

OKE, T. R. Initial Guidance to Obtain Representative Meteorological Observations at Urban Sites. IOM Report 81, WMO/TD. No. 1250. World Meteorological http://www.wmo.int/pages/prog/www/IMOP/publications/IOM-81/UrbanMetObs.pdf> Acesso em março 2015.

OKE, T.R. Siting and exposure of meteorological instruments at urban sites. In: Air Pollution Modeling and its Application XVII, Borrego, C. and A.-L. Norman, (eds.), Springer, p. 615-632, 2007.

QUENOL H., DUBREUIL V., MIMET A, PELLISSIER V., AGUEJDAD R, CLERJEAU P. ET BRIDIER S. Climat urbain et impact sur la phénologie végétale printanière. La Météorologie, $n^{\circ} 68$, p.50-57, 2010.

STEWART, I. D.; OKE, T. R. Newly developed "thermal climate zones" for defining and measuring urban heat island magnitude in the canopy layer. Preprints, T. R. Oke Symposium \& Eighth Symposium on Urban Environment, January 11-15, Phoenix, AZ, 2009.

Texto submetido à RBClima na data de 29/03/2015 